\title{
Investigating the Effect of Prior Damage on the Post-earthquake Fire Resistance of Reinforced Concrete Portal Frames
}

\author{
Hamid Reza Ronagh*, and Behrouz Behnam
}

(Received September 12, 2012, Accepted November 12, 2012)

\begin{abstract}
Post-earthquake fire (PEF) can lead to a rapid collapse of buildings that have been partially damaged as a result of a prior earthquake. Almost all standards and codes for the design of structures against earthquake ignore the risk of PEF, and thus buildings designed using those codes could be too weak when subjected to a fire after an earthquake. An investigation based on sequential analysis inspired by FEMA356 is performed here on the immediate occupancy (IO), life safety (LS) and collapse prevention (CP) performance levels of two portal frames, after they are pushed to arrive at a certain level of displacement corresponding to the mentioned performance level. This investigation is followed by a fire analysis of the damaged frames, examining the time taken for the damaged frames to collapse. As a point of reference, a fire analysis is also performed for undamaged frames and before the occurrence of earthquake. The results indicate that while there is minor difference between the fire resistances of the fire-alone situation and the frames pushed to the IO level of performance, a notable difference is observed between the fire-alone analysis and the frames pushed to arrive at LS and CP levels of performance and exposed to PEF. The results also show that exposing only the beams to fire results in a higher decline of the fire resistance, compared to exposing only the columns to fire. Furthermore, the results show that the frames pushed to arrive at LS and CP levels of performance collapse in a global collapse mode laterally, whereas at the IO level of performance and fire-alone situation, the collapse mechanism is mostly local through the collapse of beams. Whilst the investigation is conducted for a certain class of portal frames, the results confirm the need for the incorporation of PEF into the process of analysis and design, and provide some quantitative measures on the level of associated effects.
\end{abstract}

Keywords: post-earthquake fire, sequential analysis, fire resistance, reinforced concrete structures, performance-based design, immediate occupancy, life safety, collapse prevention.

\section{Introduction}

Fire in buildings is a reality and occur for many different reasons, most of which are not considered to be localized and not so serious from an urban perspective. This is mostly because there are usually adequate fireproofing systems in buildings, such as sprinklers and vertical pipes, and there exist rescue teams and fire brigades in cities to either extinguish or control the fire. Collectively, these safeguards reduce the possibility of a widespread fire. When it comes to fire after an earthquake, however, the number of available rescue teams drops, depending on the severity of earthquake, as rescue teams will also be involved with helping people trapped under the rubble. In addition, there is a high probability of active fireextinguishing systems, such as sprinklers, not working as electricity or water supplies might be cut. Thus, providing adequate time for extinguishing the fire and/or evacuating

The University of Queensland, Brisbane, QLD, Australia. *Corresponding Author; E-mail: h.ronagh@uq.edu.au Copyright $($ The Author(s) 2012. This article is published with open access at Springerlink.com people trapped in the fire must be a key aspect of a postearthquake fire (PEF) safety strategy. Past statistics have proved that PEF can create even more damage compared to the earthquake alone (Fitzpatrick 1914). The effect of PEF on buildings can be categorized into two: the damage owing to the burning of non-structural materials such as furniture and possessions; and the damage caused by excess structural loads on the building (Chen et al. 2004). The latter is important as the majority of structural members are not designed for extreme conditions, combining gravity loads, lateral loads and aftershock loads. Consequently, buildings that have been moderately damaged by an earthquake can be destroyed rapidly in a subsequent fire. From a different perspective, as earthquake can cause serious damage to lifeline structures, arterial roads and bridges, fire brigades would have increased difficulty in controlling fires. Accordingly, it will take considerably more time to control a PEF than other more usual kinds of fires. In addition, since helping people trapped under the rubble will take priority; untended fires may lead to a conflagration. In this case, it is difficult to estimate the size of the catastrophe (Scawthorn 2008). Therefore, buildings must be able to structurally resist fire for a period far longer than is the norm for fire-only design.

On the other hand, using the philosophy of design based on performance (California Seismic Safety Commission 
1996), structural elements are normally designed to satisfy various levels of performance, some of which are operational (O), immediate occupancy (IO), life safety (LS) and collapse prevention (CP). According to the performance design criteria, the expected performance of structures shall be controlled by the assignment of each structure to one of several “Seismic Use Groups". In FEMA450 (2003), for example, there are three "Seismic Use Groups", which are categorized based on the occupancy of the structures within the group and the relative consequences of earthquake-induced damage to the structures. Design codes specify progressively more conservative strength, serviceability, and detailing requirements for structures in order to attain minimum levels of earthquake performance suitable to the individual occupancies. Structures contained in these groups are not specific to a certain seismic zone; rather they are spread across all zones from high to low hazard and, as such, the categorizations do not really relate to hazard. Rather the groupings, categorized by occupancy or use, are used to establish design criteria intended to produce specific types of performance in "design earthquake" events, based on the importance of reducing structural damage and improving LS (Fig. 1).

The various performance levels required for buildings of different categories can implicitly be met by increasing the "design earthquake" by a factor called the "importance factor". The importance factor adjusts the intensity of earthquake in the design so that the required performance level under the "design earthquake" is met. Specifically, in important structures, it is expected that after an earthquake only minor damage will be sustained by the structural elements. Minor damage is quantified with a value of drift limited to $1 \%$ according to FEMA356 (2000). This is the boundary of IO and LS levels of performance. At this level of drift, while some elements go beyond the yield point in the corresponding pushover curve, non-structural components may not operate properly owing to mechanical failure or lack of amenities, such as disconnection of electricity (Behnam 2006). Therefore, when designed well, important structures are expected to remain habitable after the shock (FEMA356 2000). Structures such as schools fall into this category (Organisation for Economic Co-operation and Development 2004). Most buildings in urban areas, however, are residential or commercial buildings, designed to meet the LS level of performance. The main objective at this performance level is to limit both the amount of damage in buildings and as such more safety for the inhabitants. To meet this objective, limiting the value of drift to around $2 \%$ is recommended by FEMA356 as a margin for LS and CP levels of performance. At the LS level, it is expected that, along with some residual displacement in the building, there is considerable damage to both structural and non-structural elements. However, there should be adequate resistance left in the structure to carry the applied gravity loads without any failure. Obviously, buildings designed for CP performance level, sometimes called limited safety, will sustain more damage compared to other levels of performance. At this level, it is expected that the imposed drift would be more than $4 \%$, which can lead to extensive damage of the structural components.

Understanding the structural behavior of buildings becomes more important when a fire occurs after a seismic event, because the fire increases the level of complexity. In general, "fire-resistance rating" is defined as the period of time in which the integrity of a member subjected to fire is maintained to resist applied loads (König 2005; Kodur and Dwaikat 2007). This definition is correlated with various factors, one of which is the type of building being designed (McGhie 2007). Indeed, the purpose of fire resistance is not only to provide sufficient time to evacuate people trapped inside the burning building, but also to reduce the possibility of any conflagration (Eidinger 2004). Although typically, fire-resistance ratings are presented in national building codes, such as National Research Council Canada (2005) and International Building Code (IBC) (2006), many of them provide only for fire condition and not for PEF. This is critically important as the vulnerability of earthquake-damaged structures exposed to PEF is much more than those exposed to fire alone. This is because earthquake excitation may produce residual lateral deformations as well as residual stresses on the members (Mousavi et al. 2008). Moreover, experiences from past earthquakes confirm that both active and passive fireproofing systems, such as sprinklers and fire control systems, may become seriously damaged, thereby considerably decreasing the fire-resistance capability. Therefore, evaluation of a building's performance under PEF is essential, requiring careful scrutiny.

The PEF resistance of a building is dependent on various factors, including the deformed geometry and the degradation in stiffness resulting from earthquake (Zaharia and

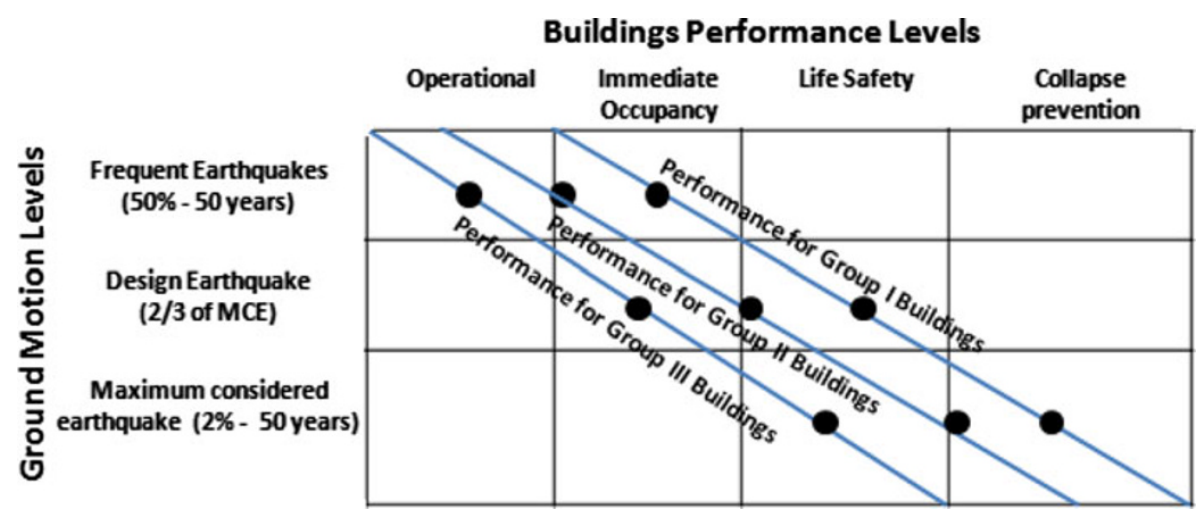

Fig. 1 Building performance levels versus earthquake severity (FEMA450 2003). 
Pintea 2009). In reinforced concrete structures, in addition to the aforementioned factors, the effects of the level of damage, including tensile cracking, removal of rebars cover and compressive crushing have to be considered as well. Assuming ductile behavior of RC elements which is often intended in design, a typical moment-curvature relation can be idealized to separate stages of pre-cracking of concrete, post cracking, yielding of steel reinforcement and concrete crushing in compression (Kwak and Kim 2002). While it seems that tensile cracking, as the first stage of cracking, has no significant effect on the PEF resistance, major cracking resulting in removal of rebars cover or crushing of concrete in compression drastically reduces the PEF resistance (Ervine et al. 2011).

Performance of buildings subjected to fire after earthquake has been investigated by researchers in the past, but has received more attention since the horrific event of ' $9 / 11$ '. For example, Della Corte et al. (2003) investigated unprotected steel moment-resistant frames and their responses when subjected to fire following an earthquake. Assuming elastic perfectly plastic (EPP) behavior of steel and considering P- $\Delta$ effect with $\mathrm{P}$ from gravity loads and $\Delta$ from the earthquake, the fire-resistance rating was found using numerical methods. Ignoring the degradation of stiffness in Della Corte et al. study is an issue subject to discussion (Fig. 2).

Further study of steel frames was carried out by Zaharia and Pintea (2009). They investigated two different steel frames, designed for two return periods of ground motion: 2,475 and 475 years. The seismic response of each structure was then evaluated by a pushover analysis developed by Fajfar (1996). While the frame designed for the 2,475 years return period remained elastic in the pushover analysis, the weaker frame designed for the 475 years return period sustained notable inter-story drift. They then performed a fire analysis on both frames, which confirmed that the fire resistance of the structures, considering their deformed state

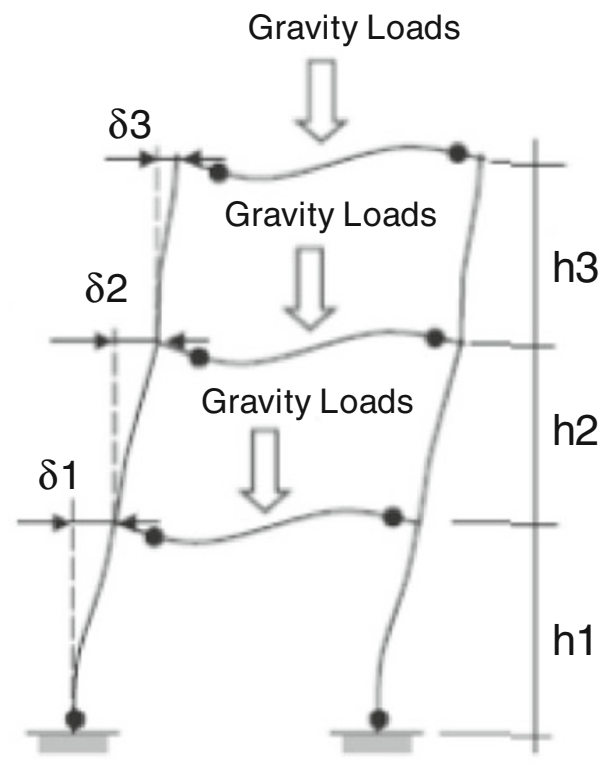

Fig. 2 Residual deformation resulting from the earthquake (Della Corte et al. 2003). under earthquake, is notably lower than that of structures that do not have any history of deformation prior to the application of the fire. Mostafaei and Kabeyasawa (2012) investigated the PEF resistance of reinforced concrete structures with shear wall. Their model was first subjected to an equivalent Kobe 1995 earthquake on a shaking table. The damage sustained by the structure was then quantified by observation, through use of a method called axial-shearflexure interaction (ASFI) (Kabeyasawa and Mostafaei 2007) in a numerical thermal analysis to find the temperature rise in and around both the cracked and the intact sections subjected to fire. Fire loading was then applied to the damaged structure in order to consider the effect of concrete's degraded compressive strength. The results showed that the ability of the structure to sustain gravity loads in the cracked components is considerably lower than in the intact components. Although the compressive strength of concrete plays an important role in the overall fire resistance, other factors (such as P- $\Delta$ effect and changes in the modulus of elasticity) have to be considered in order to improve accuracy.

In the same year, Faggiano and Gregorgio (2010) investigated steel structures exposed to PEF. They performed a coupled analysis consisting of both earthquake and fire. Based on FEMA356 procedure, Faggiano and Gregorgio developed a method for evaluating the performance of buildings subjected to earthquake, and for suggesting fire performance levels for various conditions of fire. Clearly, in a coupled analysis, both residual deformation and degradation of mechanical characteristics are applied. However, the method can be more effective for steel structures because, as was previously mentioned, in reinforced concrete structures, seriously damaged sections play an important role in PEF resistance. Recently, Ervine et al. (2011), conducted an experimental and numerical study of a reinforced concrete element subjected to conventional loads followed by a fire load. After applying two concentrated vertical loads on the specimen and recording the subsequent deflection, the created cracks were observed through the member. The model was then subjected to fire loading in order to find the effect of the created cracks on the thermal propagation inside the section. The results showed that minor tensile cracking would not significantly change the heat penetration inside the section. They concluded that the fire resistance of the intact specimen and of the minor damaged specimen were roughly identical (Ervine et al. 2012). However, exposing the rebar directly to fire, e.g. in the case of crushing of the cover, changes both the thermal and the structural behavior of the specimen considerably. Another study is currently being undertaken by Bhargava et al. (2012) on the fire resistance of an earthquake-damaged RC frame. A nearly full-scale portal frame was first loaded by the relevant gravity loads and then subjected to a cyclic lateral load, based on the Indian standard in a quasi-static fashion. The load-control mode was considered to meet $2 \%$ drift, corresponding to the LS performance level as described in FEMA356 (2000) code. The cracks widths were then observed using optical tools, non-destructive tests and 
ultrasound. A computational analysis was also performed using the finite element method with (ABAQUS 2008) to compare the test and the analytical results. The results show a good conformity with FEMA356 descriptive definitions of damage levels at various performance levels, such as IO and LS. They suggested that the results of a quasi-static cyclic test can be used for the subsequent fire analysis.

Aligned with the abovementioned studies and the FEMA356 performance level definition, in this study, a series of numerical investigations is carried out on the PEF resistance of two portal frames, designed for different performance levels. The study here includes a sequential analysis comprising both earthquake and the aftermath fire and using FEMA356 descriptive performance levels. As well, consideration is given to effects such as the removal of cover on the PEF resistance.

\section{Methodology}

\subsection{Sequential Analysis}

Sequential analysis is a useful method for considering the effect of both earthquake and fire on a structure. Figure 3 schematically shows stages of the nonlinear sequential analysis. The first stage of loading is the application of gravity loads, which are assumed to be static and uniform. A pseudo earthquake load then follows in a pushover style, reaching its maximum value and returning to zero in a short time. Clearly, during this time, gravity loads are also applied. The pattern that is chosen for applying the earthquake load is similar to pushover analysis, with the difference that the structure is unloaded after reaching a certain level of load. Here, it is assumed that the maximum level of earthquake load corresponds to the defined performance level, i.e. IO, LS or CP, according to FEMA356 (2000). This assumption is in line with the seismic design philosophy in which the performance level of structures shall not exceed the assumed level when subjected to the "design earthquake". Therefore, the structures are pushed to these levels and then unloaded.

Load duration is not important for either gravity or earthquake loads, because in this study long-term effects such as creep and shrinkage are not included in the analysis. Thus, any arbitrary load duration could be chosen for these loads. It should be noted that no dynamic effects are considered in this study. Finally, as can be seen in Fig. 3c, the fire load is applied to the structure. Prior to fire loading, properties of the structures are set to the reference temperature, but during fire, the mechanical properties vary with temperature.

In this study, SAFIR software (Franssen 2011) is used to perform the seismic and subsequent fire analyses sequentially.

\subsection{Material Nonlinearity}

Fiber element is the most capable model for the nonlinear analysis of reinforced concrete members. Many researchers have developed the finite element formulation for this element. The model accounts for material nonlinearities in rebar steel and concrete (Zhao and Sritharan 2007; Lin et al. 2009; Godat 2008). A fiber beam element is made up of a series of sections along the element length, whose number and location depend on the integration scheme. The constitutive relation of the section is not specified explicitly, but is derived by integration of the response of the fibers, which follow the uniaxial stress-strain relation of the particular material. The consecutive material stress-strain curves are used to generate the moment-curvature and the axial forcedeformation relationships. Concrete can be modeled depending on the region: the core (that is confined); and the cover (that is unconfined). In the SAFIR program, the stressstrain relationship for concrete and rebar steel are embedded according to Eurocodes (Minson 2006). Using the fiber model, the spread of plasticity can be modeled appropriately. Unlike the lumped plasticity model, in the fiber element model, the plasticity is spatially distributed both in cross section and along the member.

\subsection{Pushover Analysis}

Static pushover analysis is one of the non-linear static methods used for analyzing structures subjected to seismic loads. This method is becoming a popular tool for the seismic performance evaluation of existing and new structures (Fardis 2007). In this method, using a specific load pattern, the structure is pushed to a value of displacement called the target displacement. The target displacement serves as an estimate of the global displacement that the structure is expected to experience in a "design earthquake", often shown by the roof displacement at the center of mass of the structure. In this study, a vertical distribution of loads, proportional to the shape of the fundamental mode in the direction under consideration, is used. Figure 4 shows a structural frame subjected to a lateral load pattern and a

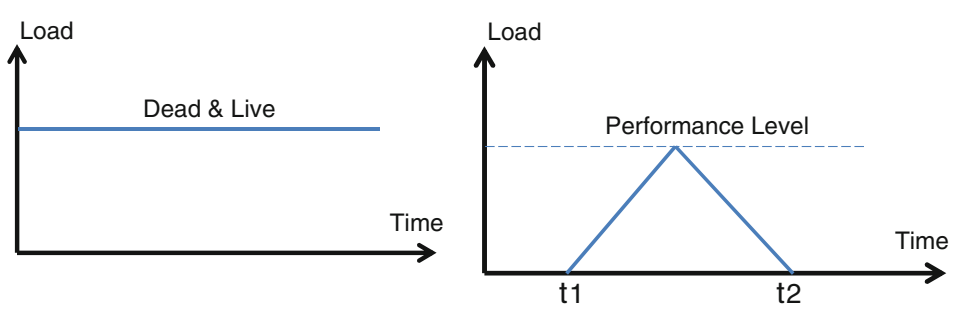

(a)

(b)

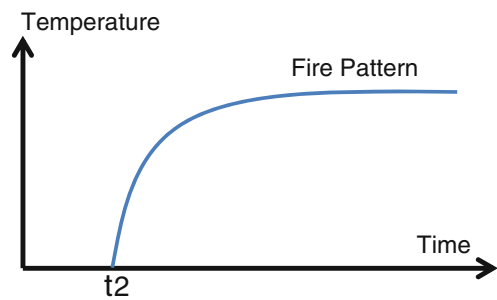

(c)

Fig. 3 Stages of the sequential analysis. a Gravity loading (is constant during the time). b Earthquake loading (is applied for a short time). c Fire loading (is applied after the unloading process of earthquake loads). 


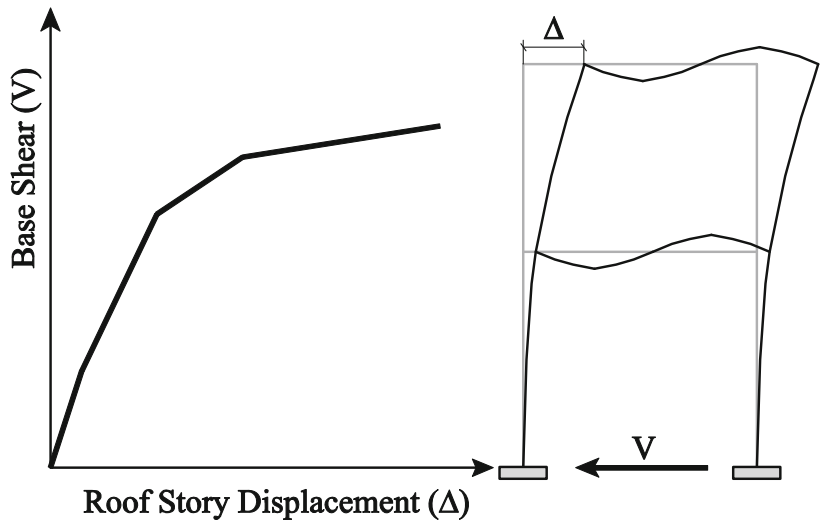

Fig. 4 Conceptual pushover curve.

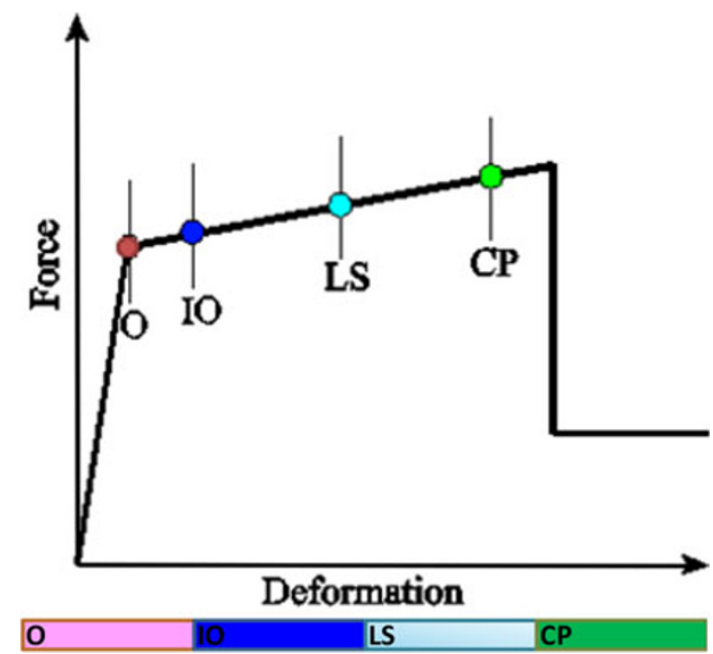

Fig. 5 Conceptual plastic hinge states. $O$ operational, $I O$ immediate occupancy, $L S$ life safety, $C P$ collapse prevention.

typical base shear versus top story displacement. In this study, the IO, LS and CP performance levels are considered for seismic analysis prior to fire loading. Clearly, in structures that experience plastic deformations, residual deformation remains in the structure and thus the structures do not return to their initial condition. Using the definition of lumped plasticity, the potential locations of plasticity are introduced by plastic hinges in SAP2000 (2002).
The moment-rotation behavior of each plastic hinge follows FEMA definition. Figure 5 shows a typical forcedeformation curve for an assumed hinge. This figure also shows the performance levels as mentioned earlier.

These definitions in a concrete cross section are required for the PEF analysis, because variation of temperature across the section is highly dependent on the state of damage. In FEMA356, it is stated that in the IO performance level, minor damage in the structural elements is observed, which has no significant effect on PEF resistance (Ervine et al. 2012). On the other hand, in the LS performance level, extensive damage is observed in beams and ductile columns, resulting in spalling of their cover. In addition, for structures designed for CP level of performance, it is expected that the structure would sustain considerable damage in beams and columns, much more than for IO or LS levels of performance. The dotted lines and the arrows in Fig. 6 show the assumed pattern of applied fire frontier for damaged beams and columns after the pushover analysis. This assumption is based on the authors' interpretation of the information available in the FEMA356 code, the Japan Building Disaster Prevention Association (JBDPA) and an experimental study performed by Bhargava et al. (2012). While none of the aforementioned references differentiates between the beam and the column responses as to the extent of cracking or concrete spalling, they all point to the fact that the concrete cover is no longer part of the section. In FEMA356, "Table C1-3 structural performance levels and damage", the different levels of damage in columns and beams are explained. Relating to quantity rather than quality, Bhargava et al. (2012) conducted an experimental study on a nearly fullscale RC frame, in order to find the level of damage when the frame was pushed to a certain level of displacement. Their results show that while at a roof drift ratio of $1.37 \%$, flexural cracking was observed (corresponding to the drift ratio in IO level of performance), at $2.11 \%$ drift ratio (corresponding to the drift ratio of LS level of performance) spalling and wide cracks in columns and beams were observed. The study does not reveal any differences between the columns and the beams. Based on JBDPA, Meada and Kang (2009) and Nakano et al. (2004) showed in several studies that when a structure sustains severe damage (corresponding to the $\mathrm{CP}$ performance level in FEMA356)

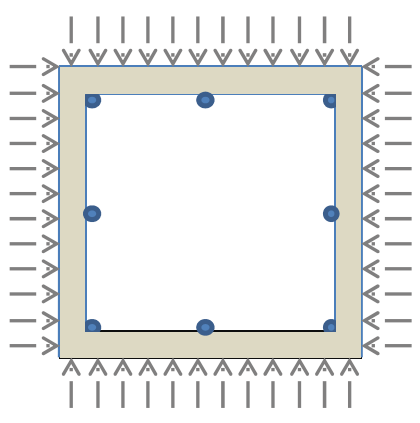

(a)

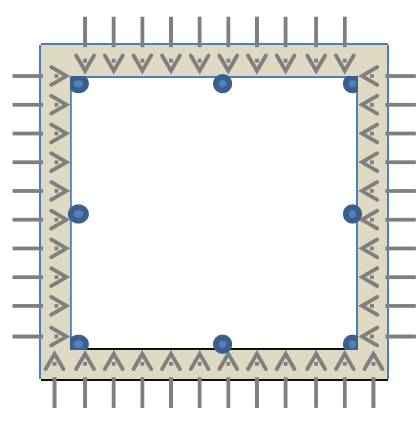

(b)

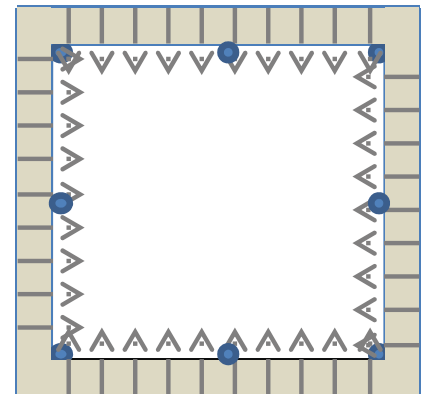

(c)

Fig. 6 Schematically applied fire frontiers on the sections in various performance levels. a IO level of performance. b LS level of performance. c CP level of performance. Note the arrows show fire frontiers. 


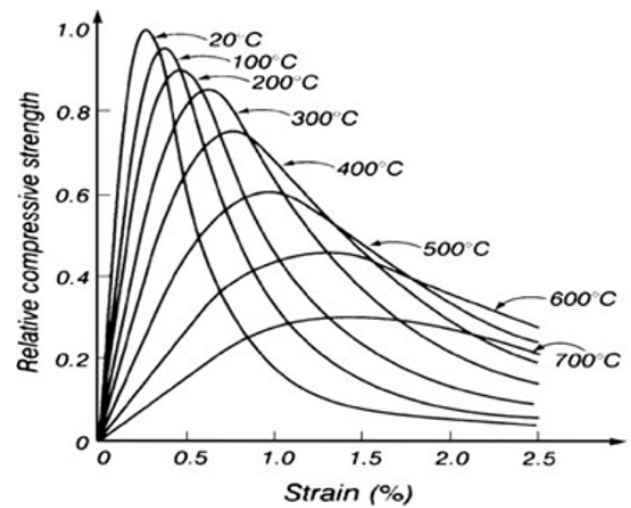

(a)

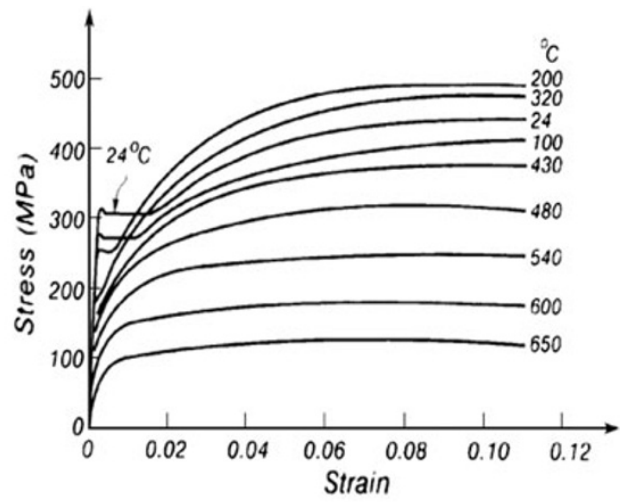

(b)

Fig. 7 Stress-strain relationship at different temperatures (Minson 2006). a Concrete. b Hot-rolled bar.

crushing and spalling of the concrete cover with consequent exposed reinforcement is observed.

Overall, the PEF analysis in structures designed for IO level of performance is only followed by a minor residual displacement, while at LS level of performance, along with some residual deformation and degradation in strength and stiffness, the removal of cover in a region around the plastic hinges should be considered. At CP level of performance, however, the structures not only sustain severe damage and considerable degradation in strength and stiffness, but rebars also need to be considered totally exposed in the PEF analysis.

\subsection{Reinforced Concrete Behavior Under the Effect of Fire}

Materials thermal and mechanical characteristics change considerably when exposed to fire, which in many cases produce high levels of thermal stress (Kwasniewski 2011). In addition, when a heterogeneous composite material with different thermal characteristics is subjected to elevated temperature, differential thermal stresses speed up the degradation. Concrete has low thermal conductivity, which creates slow transmission of heat inside the cross section (Faggiano and Gregorgio 2010). The reinforcement bars have high thermal conductivity, but they are generally protected by the concrete cover. Cracking or crushing of the concrete cover, however, causes more thermal propagation to penetrate at a quicker rate with serious negative outcomes. It is apparent that this penetration can be worse if a member that has been previously damaged (for example, as a result of earthquake loading), experiences high temperature, because the fire resistance of seriously damaged members is much less than that of intact members. In other words, the higher the number of damaged members and the greater the extent of damage in these members, the shorter will be the time to collapse during the PEF. In particular, for reinforced bars, the critical temperature is around $500{ }^{\circ} \mathrm{C}$, at which steel's ultimate strength decreases by $50 \%$, while for concrete, the critical temperature is about $300{ }^{\circ} \mathrm{C}$ (Youssef and Moftah 2007). "Critical temperature" is defined as the temperature beyond which the values of strength are considerably reduced. Figure 7 shows the stress-strain relationship in hotrolled bars and concrete at high temperatures, as developed by Eurocodes 2 and 3. It is also worth mentioning that spalling of concrete cover under fire exposure is an important issue, which occurs suddenly, violently, is brittle and may lead to a significant decrease in the load-bearing of the structure (Debicki et al. 2012). The thermal spalling, nevertheless, is more important in the elements with more than 4-5 cm cover (Majorana et al. 2010) or made of highstrength concrete (HSC) (Kodur 2005) with particles smaller than the cement grains (micro silica, for example) and moisture content of more than 3-4\% (Hertz 2003; Hertz and Sørensen 2005). As for the elements of this study, which are made from normal-strength concrete (NSC) with the cover of $4 \mathrm{~cm}$ and moisture of $2 \%$, thermal spalling is not considered.

\subsection{Fire Patterns}

Several methods have been developed to calculate the thermal actions produced by a fire on a compartment (Remesh and Tan 2007; Lundin 2005). These methods have been established either using parametric fires called "timetemperature curves", such as those mentioned in ISO 834 International Standard (1999) and ASTM E119 (ASTM 2006) (based on experiment and tests), or using "natural fires" which rely mainly on the volume of gas produced by the combustible materials in a covered space, such as those stated in SEI and ASCE (2006). Both models are represented assuming a fully developed fire, as schematically shown in Fig. 8. The temperatures produced from burning combustible materials are combined into one single parameter (Buchanan 2001).

The cooling phase in Fig. 9 (the dotted line) is based on the assumption that after a fire has been burning for some time, either air or combustible material will become less available and thus, the temperature or fire load will decrease. This assumption is more realistic in the case of fire before earthquake, assuming closed openings. However, in buildings previously damaged by an earthquake, there is a high probability of window breakage. As a result, the pattern of fire progression is different compared to a "normal" fire. 


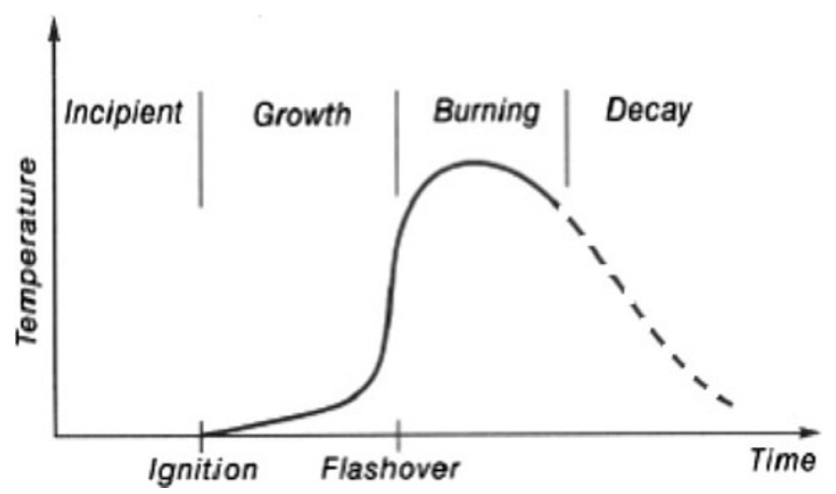

Fig. 8 Temperature-time curve for fully developed fire (Buchanan 2001).

Consequently, there is a strong recommendation to use the curve without decay as shown in Fig. 10 for a PEF event (Tanaka 1998).

To calculate the fire resistance of the selected models in this study, a computer program written based on finite element method (FEM) called SAFIR is employed. This program performs nonlinear analyses on one, two or three dimensional structures in which both geometrical and material nonlinearity are taken into account. The analyses can also be performed under ambient or elevated temperature. The stress-strain relationships for various materials, as well as their thermal characteristics, are embedded in the software, according to Eurocodes. Meanwhile, accounting for thermal action in a structure, both 'time-temperature curves' and 'natural fire' can be used. Structures that have been exposed to fire are analyzed in two stages, thermal analysis and structural analysis. In the thermal analysis, the temperature inside the cross sections at every thermal step is stored to be used for the subsequent structural step. For the purpose of this study, the time-temperature curve according to ISO 834 without cooling phase is used, as shown in Fig. 9.

\section{Case Studies}

Two portal reinforced concrete frames designed based on ACI 318-08 code with different geometry are pushed to arrive at different lateral drifts, corresponding to IO, LS and $\mathrm{CP}$ levels of performance, and using pushover analysis as schematically shown in Fig. 10. The properties of the designed frames are presented in Fig. 11. The frames are made using NSC with compressive strength of $25 \mathrm{MPa}$ and longitudinal and transverse reinforcing bars with yield stress of $400 \mathrm{MPa}$. The frames are dimensioned for a height of $3.0 \mathrm{~m}$ and load combinations of $8.0 \mathrm{kPa}$ for dead load and $2.5 \mathrm{kPa}$ for live load. The combination of $100 \%$ dead load and $20 \%$ live load is used to find the required mass for calculating the earthquake load (ACI318 2008). Furthermore, the frames are exposed to standard fire (ISO834 curve, without decay) and three different situations of fire: only beams, only columns and the whole of the frame. For the

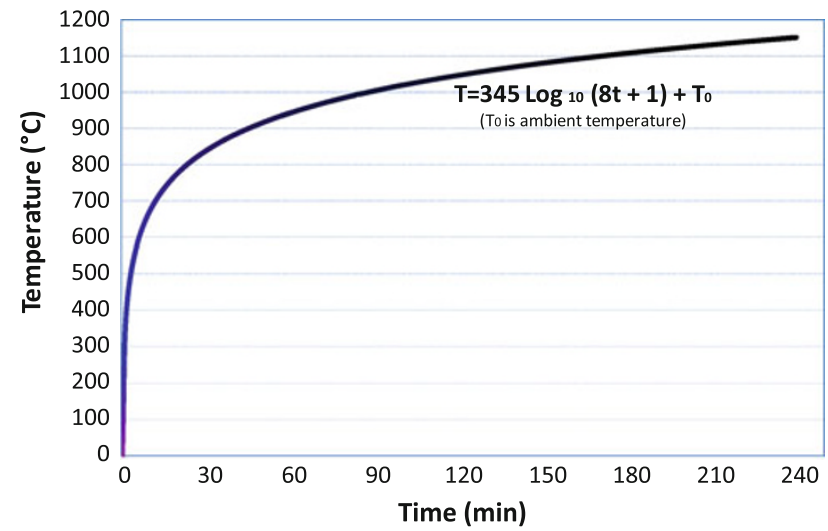

Fig. 9 Fire pattern according to ISO834.

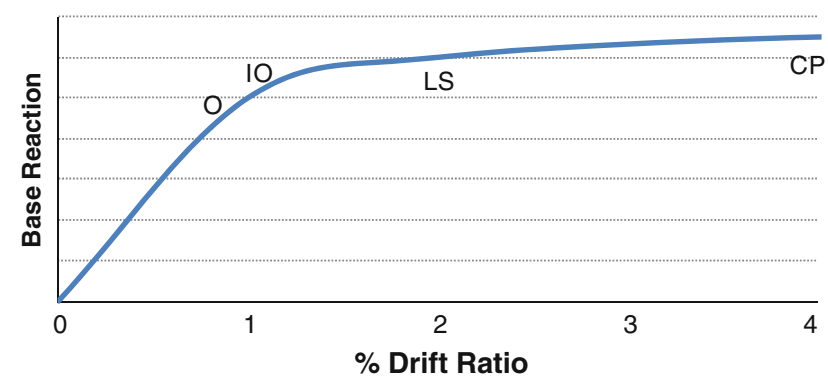

Fig. 10 Pushover curve. $O$ operational, $I O$ immediate occupancy, $L S$ life safety, $C P$ collapse prevention.

thermal analysis, it is assumed that the concrete moisture content is $20 \mathrm{~kg} / \mathrm{m}^{3}$. Moreover, the thermal expansion coefficient of rebar and concrete are assumed to be

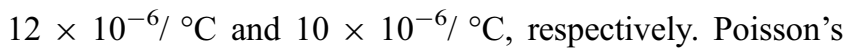
ratio of 0.2 is considered for the concrete.

In order to improve our understanding of the behavior, the fire analyses are also performed for the undeformed frames, i.e. before occurrence of the earthquake. It must be noted that the exterior sides of the columns are not exposed to fire, as it is assumed that the fire initiates from the inside of the compartment. Meanwhile, only three sides of the beams are exposed to fire, because it is generally assumed that the top side of a beam is protected by the concrete slab.

\section{Results}

The sequential analysis comprises three main stages, which are gravity loading, followed by seismic pushover analysis, and finally PEF. In the seismic analysis, the structure is subjected to a monotonically increasing lateral load to meet the specified performance levels. Indeed, the structure is pushed to a certain level of displacement. Accordingly, three different levels of performance, i.e. IO, $\mathrm{LS}$, and CP, are met after the pushover analysis. Using FEMA356 procedure, the accounted-for target displacement is used for performing the pushover analysis in the mentioned performance levels. In this respect, the SAP2000 

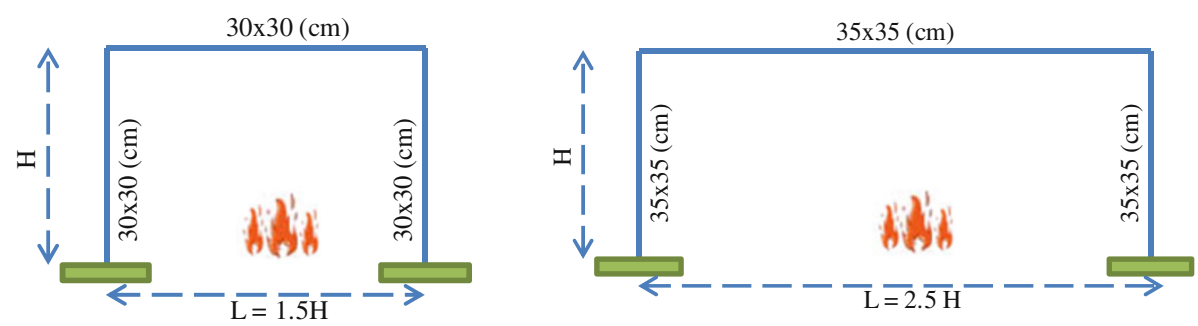

Fig. 11 Geometric properties of selected frames, $\mathrm{H}=3.0 \mathrm{~m}$. Note for all the structural members, $4 \mathrm{~cm}$ cover is assumed.

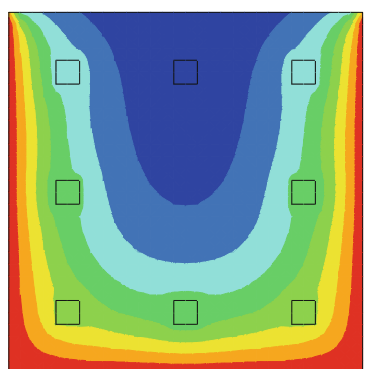

(a)

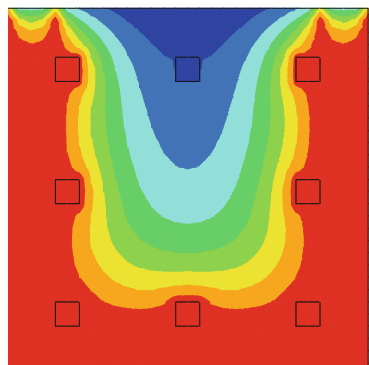

(b)

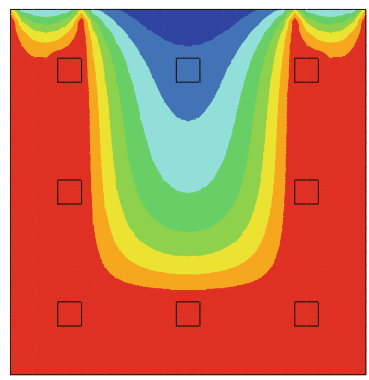

(c)

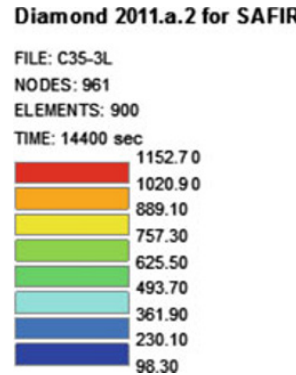

(d)

Fig. 12 Distribution of temperature in a column according to ISO 834. a IO level of performance. b LS level of performance. c CP level of performance. d Temperature.

(2002) program is employed to perform the nonlinear pushover analysis. Furthermore, FEMA procedure is used to define the hinges for the nonlinear pushover analysis. The lateral forces corresponding to the target displacement at every performance level are extracted from the SAP2000 (2002) program, and are then input to the SAFIR program for performing the sequential analysis. Final stage of the sequential analysis is to apply a PEF to the frames. As mentioned, several scenarios are used for the fire analysis; in one case, the undamaged frame is subjected to fire loading, while in the second case, the damaged frame is exposed to fire load. In this way, in the first case, the fire load follows the gravity loads, but in the second case, the fire load follows gravity and earthquake loads. Figure 12 shows the temperature distribution in a column at different levels of damage, from minor to major.

Figures 13 and 14 show displacement against time for the case of $\mathrm{L}=1.5 \mathrm{H}$, which implies the fire resistance of the frames in seconds for both scenarios (fire and PEF). The fire resistance is defined as the time at which the displacements, either globally (i.e. the drift of a certain point) or locally (i.e. the deformations at the middle of a beam), go beyond chosen thresholds. The thresholds have been identified by the curve for displacements versus time step merging towards a vertical asymptote by $1 \%$ error. These thresholds implicitly represent the definition of fire resistance of a member as described earlier, where the member is not able to resist the initially applied gravity loads (Kodur and Dwaikat 2007). As is seen in the figures, regardless of subjecting a structure to fire alone or PEF, there is a correlation between the fire-resistance rating and the performance levels. Indeed, along with increasing the lateral displacement in the frames, the fire resistance decreases such that the fire resistance of the frames pushed to $\mathrm{CP}$ level of performance is much lower than that of the frames pushed to LS or IO levels of performance. The
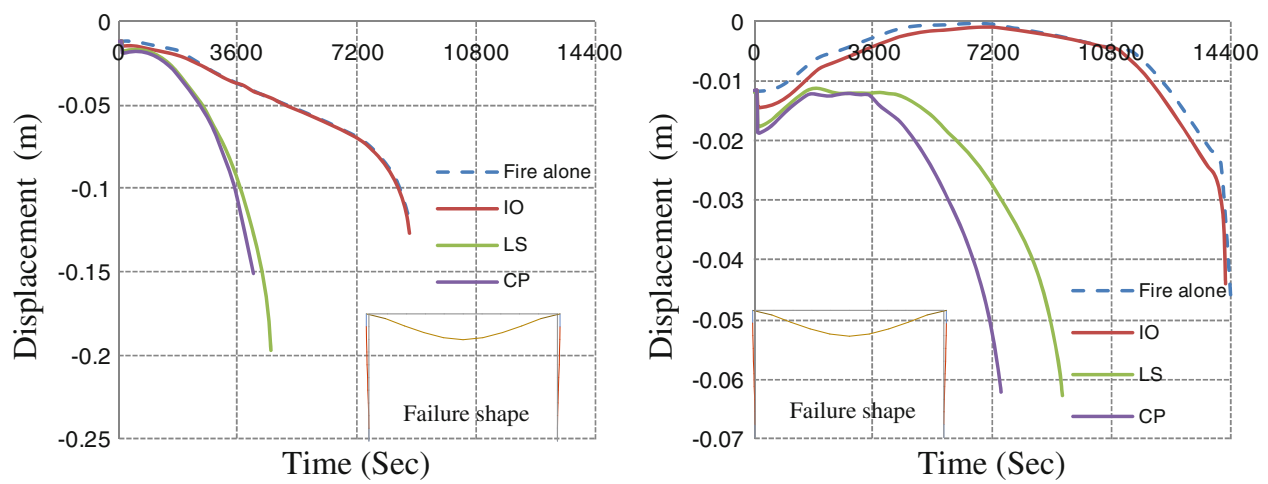

Fig. 13 Fire resistance of the case " $\mathrm{L}=1.5 \mathrm{H}^{\prime}$, members separately exposed to fire. a Only the beam exposed to fire. b Only the columns exposed to fire. $I O$ immediate occupancy, $L S$ life safety, $C P$ collapse prevention. 

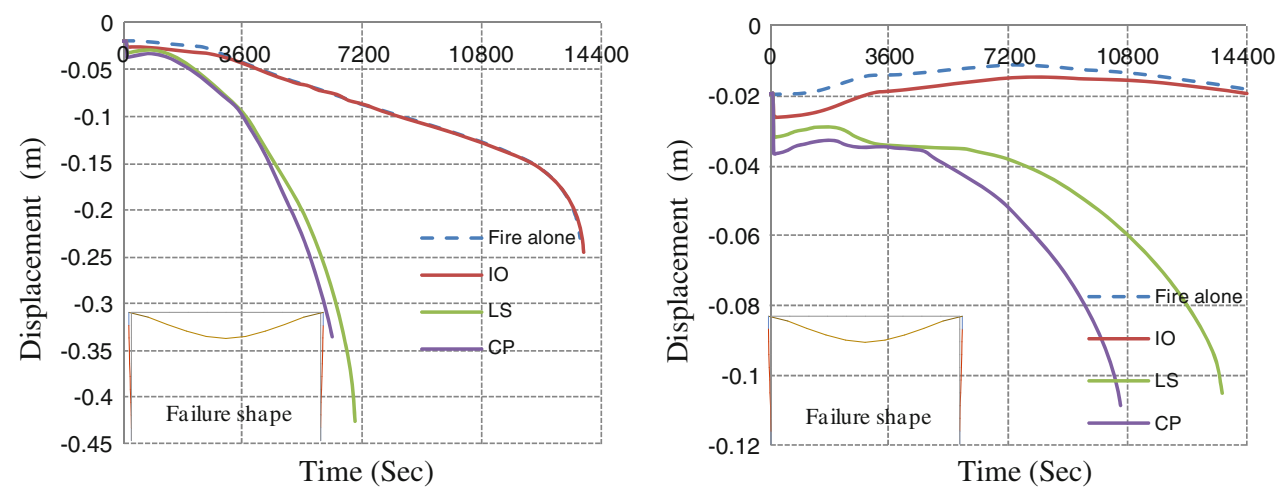

Fig. 14 Fire resistance of the case " $\mathrm{L}=1.5 \mathrm{H}$ ", members separately exposed to fire. a Only the beam exposed to fire. $\mathbf{b}$ Only the columns exposed to fire. $I O$ immediate occupancy, $L S$ life safety, $C P$ collapse prevention.
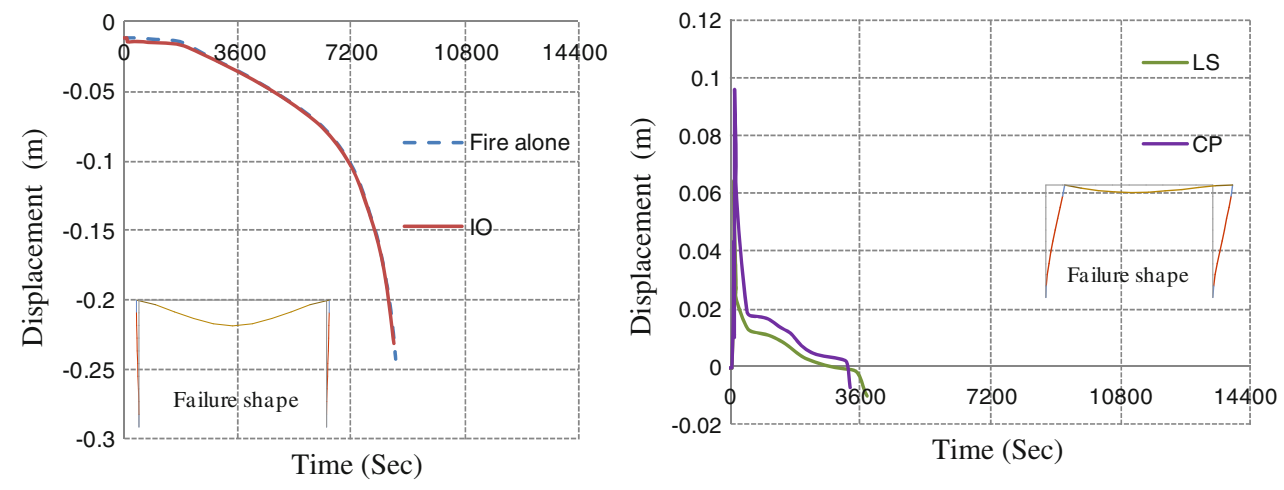

Fig. 15 Fire resistance of the case " $\mathrm{L}=2.5 \mathrm{H}$ ", all the members exposed to fire. a Fire alone and IO level. $\mathbf{b} \mathrm{LS}$ and $\mathrm{CP}$ level. $I O$ immediate occupancy, $L S$ life safety, $C P$ collapse prevention.
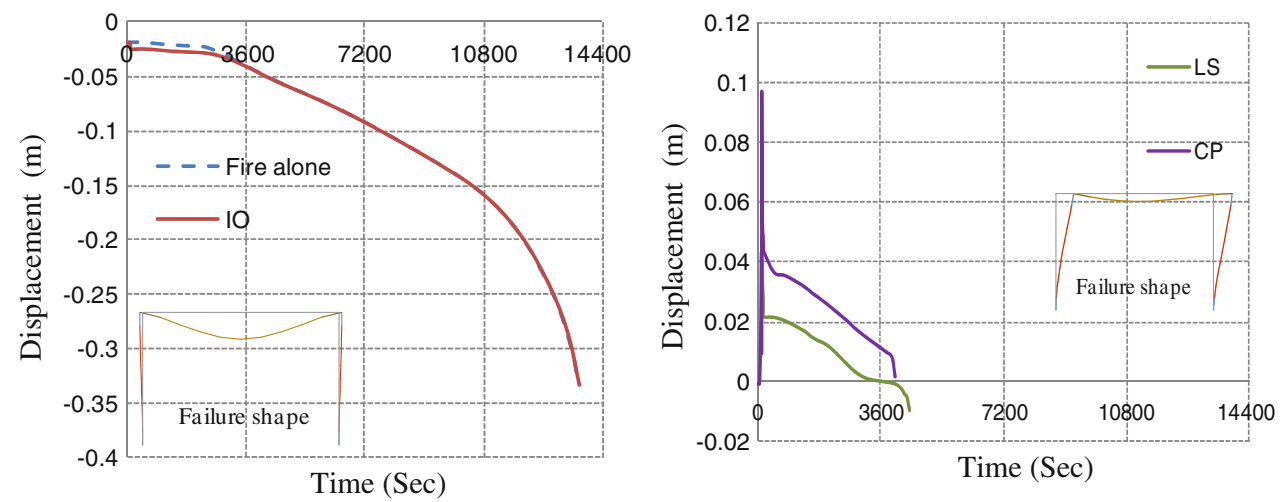

Fig. 16 Fire resistance of the case " $\mathrm{L}=2.5 \mathrm{H}$ ", all the members exposed to fire. a Fire alone and IO level. $\mathbf{b} \mathrm{LS}$ and $\mathrm{CP}$ level. $I O$ immediate occupancy, $L S$ life safety, $C P$ collapse prevention.

figures also show a minor difference between the fire resistance at IO level of performance and fire alone. That is mostly because at IO level of performance, only minor damage occurs, resulting in insignificant residual displacement and/or degradation in strength and stiffness. It is also seen that fire resistance declines considerably when only the beam is exposed to fire, compared to exposing the columns to fire. In other words, it seems that the beam is more sensitive to fire than the columns. Interestingly, Figs. 13 and 14 show that there is similarity in fire resistance when all members are exposed to fire and when only the beam is exposed to fire. This implies that the fire resistance of a frame is mostly dependent on the fire resistance of the beams. In the figures, the shape of failure is shown. As is seen, two types of failure are observed; local and global. While local collapse depends largely on the collapse of beams (Figs. 13a, b, 15a), global collapse is mainly governed by considerable lateral displacement of the columns (Fig. 15b). It is evident that the frame fails locally in case of fire alone and the IO level of performance. However, it fails globally when pushed to LS or CP levels of performance. The sharp increase and then decrease in Fig. 15b represents the displacement resulted from lateral pushover. 
Figures 14 and 16 show the fire resistance of the frame with $\mathrm{L}=2.5 \mathrm{H}$, for different positions of fire. Similar to the frame with $\mathrm{L}=1.5 \mathrm{H}$, the fire resistance reduces when the frame is more pushed laterally. Again, there is similarity between the fire resistance when the whole frame is exposed to fire and that when only the beam is exposed to fire, which again signifies that the fire resistance of the frames depends mostly on the fire resistance of the beam. As a specific note with regard to Fig. 16b, it is useful to mention that while the frame fails in case of PEF at the LS or CP level of performance, no failure is observed even after $4 \mathrm{~h}$ in case of fire alone or PEF at IO level of performance. Besides, as it is seen in Figs. 14 and 16, global collapse is observed in the frame if pushed to the LS or CP level of performance. However, the frame fails locally in the other fire scenarios.

In general, the fire resistance of the frame with $\mathrm{L}=2.5 \mathrm{H}$ is greater than that of the frame with $\mathrm{L}=1.5 \mathrm{H}$ because of more stiffness in the frame with $\mathrm{L}=2.5 \mathrm{H}$. However, there is a close similarity between the fire resistances of both frames when subjected to PEF.

\section{Conclusion}

Post-earthquake fire is one of the most problematic situations in seismic regions. In this research, sequential nonlinear analysis is proposed for PEF. Two RC frames $(\mathrm{L}=1.5 \mathrm{H}$ and $\mathrm{L}=2.5 \mathrm{H}$, where $\mathrm{H}=3.0 \mathrm{~m}$ ) were selected and then pushed to arrive at three different lateral displacements corresponding to three different performance levels, i.e. IO, LS and CP. That is, the maximum allowable interstory drift was assumed to satisfy the mentioned performance levels. Pushover curves were then extracted for use in the subsequent analysis. Sequential loading, consisting of gravity and lateral loads followed by fire loads, was a key aspect of the study, conducted using SAFIR software. In SAFIR, the P- $\Delta$ effect and the residual lateral deformation as well as degradation in stiffness were considered. Defining the damaged sections (in terms of spalling of cover and such) in the thermal analysis was an additional factor considered in the fire analysis. The patterns of damage were drawn from the descriptive definition of FEMA356 and other numerical and experimental studies as mentioned earlier, and for buildings designed for different performance levels. Accordingly, the following remarks can be made:

- While there exist no computer program that can trace the response of an element in the full range of loading consisting of gravity loads, earthquake loads and fire loads up to collapse; sequential analysis using a combination of softwares and simplifications as performed here is proved to be a functional tool for considering the effect of residual deformations resulted from an earthquake, as well as degradation in stiffness and strength while performing the fire analysis.

- In the frame with $\mathrm{L}=1.5 \mathrm{H}$, there was a considerable difference between the results of fire-alone and PEF resistance when the frame was pushed to arrive at LS and
$\mathrm{CP}$ level of performance. However, the fire resistance of fire-alone situation and IO level of performance were roughly identical. The results showed that while the fire resistance in fire-alone situation was about $2 \mathrm{~h}$ and $30 \mathrm{~min}$, it reduced to about 70 and $50 \mathrm{~min}$ at the LS and CP level of performance, respectively.

- In the frame with $\mathrm{L}=2.5 \mathrm{H}$, there was also a significant difference between the results of fire-alone and PEF resistance when the frame was pushed to arrive at LS and CP level of performance. Again, the fire resistance of fire-alone and IO level of performance were approximately identical. However, the fire resistance of firealone situation from about $3 \mathrm{~h}$ and $40 \mathrm{~min}$, reduced to about 90 min when the frame was pushed to arrive at the LS level of performance and to around $70 \mathrm{~min}$ at the CP level of performance.

- Structures that have significantly suffered damage from earthquake loads have lower fire resistance than undamaged structures. This can result from residual lateral displacements, degradation in strength and stiffness, or the direct heating of the steel reinforcement as a result of removal of cover, exacerbating the effects of fire.

- It was observed in both frames and both situations, before and after earthquake, that the fire resistance rating when the entire frames are exposed to fire is largely similar to the situation when only beams are exposed to fire. In other words, the fire resistance of the frames is mostly dependent of the resistance of the beams.

- Two types of collapse mechanisms were observed during the fire analysis. While global collapse occurred in the frames subjected to PEF at LS and CP levels of performance, local collapse happened in the fire-only case and PEF at IO level of performance. The global collapse occurred mostly because of considerable lateral movement of the columns, while the local collapse occurred because of collapse of the beams.

- Further studies need to be performed, either numerically or experimentally, particularly on different stories and different fire positions, in order to develop a better understanding of this issue

\section{Open Access}

This article is distributed under the terms of the Creative Commons Attribution License which permits any use, distribution, and reproduction in any medium, provided the original author(s) and the source are credited.

\section{References}

ABAQUS 6.8. (2008). Providence: Dassault Systemes Simulia Corp.

ACI318. (2008). Building code requirements for structural concrete (ACI 318-08) and commentary. Farmington Hills, Michigan, USA: American Concrete Institute. 
ASCE. (2006). Minimum design loads for buildings and other structures. SEI/ASCE 7-0.5. Reston, Virginia, USA: American Society of Civil Engineers.

ASTM. (2006). Standard test methods for determining effects of large hydrocarbon pool fires on structural members and assemblies. ASTM E1529-06. USA: American Society for Testing and Materials.

Behnam, B. (2006). Retrofitting management for residential buildings (p. 195). Tehran, Iran: Tehran Polytechnic.

Bhargava, P., Sharma, U. K., Singh, Y., Singh, B., Usmani, A., Torero, J., Gillie, M., Pankaj, P., May, I., \& Manohar, C.S. (2012). Fire testing of an earthquake damaged RC frame. In Sixth international conference, structures in fire. Lancaster, Pennsylvania, USA: DEStech Publications.

Buchanan, A. (2001). Structural design for fire safety. New York, USA: Wiley.

California Seismic Safety Commission. (1996). Seismic evaluation and retrofit of concrete buildings (ATC 40), in Chapter 2, Overview. Sacramento, California, USA: California Seismic Safety Commission.

Chen, S., Lee, G. C., \& Shinozuka, M. (2004). Hazard mitigation for earthquake and subsequent fire. In Annual meeting: Networking of young earthquake engineering researchers and professionals in Honolulu. Buffalo, New York, USA: Multidisciplinary Centre for Earthquake Engineering Research.

Debicki, G., Haniche, R., \& Delhomme, F. (2012). An experimental method for assessing the spalling sensitivity of concrete mixture submitted to high temperature. Cement \& Concrete Composites, 34(8), 958-963.

Della Corte, G., Landolfo, R., \& Mazzolani, F. M. (2003). Post earthquake fire resistance of moment resisting steel frames. Fire Safety Journal, 38(7), 593-612.

Eidinger, J. M. (2004). Fire following earthquake-flex house, in 13th world conference on earthquake engineering (p. 3268). Vancouver, Canada: Canadian Association for Earthquake Engineering.

Ervine, A., Gillie, M., Stratford, T. J., \& Pankaj, P. (2011). Thermal diffusivity of tensile cracked concrete. In International conference applications of structural fire engineering, Prague, pp. 97-102.

Ervine, A., Gillie, M., Stratford, T. J., \& Pankaj, P. (2012). Thermal propagation through tensile cracks in reinforced concrete. Journal of Materials in Civil Engineering, 24(5), 516-522.

Faggiano, B., \& Gregorgio, D. (2010). Assessment of the robustness of structures subjected to fire following earthquake through a performance-based approach. Urban habitat constructions under catastorphic events. London, UK: Taylor \& Francis.

Fajfar, P. (1996). The N2 method for the seismic damage analysis of RC buildings. International journal of Rock Mechanics and Mining Sciences and Geomechanics, 33(6), A276.

Fardis, M. (2007). Guidelines for displacement-based design of buildings and bridge. In Risk mitigation for earthquake and landslides. Italy: IUSS Press.
FEMA356. (2000). Prestandard and commentary for the seismic rehabilitation of buildings: FEMA356, in rehabilitation requirements. Washington, DC, USA: Federal Emergency Management Agency (FEMA).

FEMA450. (2003). Recommended provisions for seismic regulations for new buildings and other structures, in Part 1. Washington, DC, USA: National Institute of Building Sciences.

Fitzpatrick, F. (1914). Fireproof construction. Chicago: American School of Correspondence.

Franssen, J. M. (2011). User's manual for SAFIR 2011 a computer program for analysis of structures subjected to fire. Liege: University of Liege.

Godat, A. (2008). Finite element modelling of externally shearstrengthened beams using fibre reinforced polymers. Sherbrooke, Canada: Universite de Sherbrooke.

Hertz, K. D. (2003). Limits of spalling of fire-exposed concrete. Fire Safety Journal, 38(2), 103-116.

Hertz, K. D., \& Sørensen, L. S. (2005). Test method for spalling of fire exposed concrete. Fire Safety Journal, 40(5), 466-476.

International Building Code (IBC). (2006). Facilities 3. NFPA 101-100. USA: National Fire Protection.

ISO 834 International Standard. (1999). Fire resistance tests, ISO 834-1, in Test conditions, International Standard. p. 31.

Kabeyasawa, T., \& Mostafaei, H. (2007). Axial-shear-flexure interaction approach for reinforced concrete columns. ACI Structural Journal, 104(2), 218-226.

Kodur, V. K. R. (2005). Guidelines for fire resistance design of high-strength concrete columns. Journal of Fire Protection Engineering, 15(2), 93-106.

Kodur, V. K. R., \& Dwaikat, M. (2007). Performance-based fire safety design of reinforced concrete beams. Journal of Fire Protection Engineering, 17, 293-320.

König, J. (2005). Structural fire design according to Eurocode 5: Design rules and their background. Fire and Materials, 29(3), 147-163.

Kwak, H.-G., \& Kim, S.-P. (2002). Nonlinear analysis of RC beams based on moment-curvature relation. Computers \& Structures, 80(7-8), 615-628.

Kwasniewski, A. (2011). Analyses of structures under fire. Warsaw, Poland: Warsaw University of Technology.

Lin, H., Clifford, M. J., Long, A. C., \& Sherburn, M. (2009). Finite element modelling of fabric shear. Modelling and Simulation in Materials Science and Engineering, 17(1), 015008 .

Lundin, J. (2005). On quantification of error and uncertainty in two-zone models used in fire safety design. Journal of Fire Sciences, 23(4), 329-354.

Majorana, C. E., Salomoni, V. A., Mazzucco, G., \& Khoury, G. A. (2010). An approach for modelling concrete spalling in finite strains. Mathematics and Computers in Simulation, 80(8), 1694-1712.

McGhie, C. (2007). Apparent level of safety of buildings meeting the New Zealand building code approved document C/AS1: fire safety (p. 280). Christchurch, New Zealand: University of Canterbury. 
Meada, M., \& Kang, D. (2009). Post-earthquake damage evaluation of RC buildings. Journal of Advanced Concrete Technology, 7(3), 327-335.

Minson, A. (2006). Eurocode 2-3. Concrete Structures, 40(1), $30-31$.

Mostafaei, H., \& Kabeyasawa, T. (2012). Performance of a sixstory reinforced concrete structure in post-earthquake fire. In 10th Canadian Conference on Earthquake Engineering. Toronto, Canada: Institute for Research in Construction.

Mousavi, S., Kodur, V. K. R., \& Bagchi, A. (2008). Review of post earthquake fire hazard to building structures. Canadian Journal of Civil Engineering, 35(7), 689-698.

Nakano, Y., Maeda, M., Kuramoto, H., \& Murakami, M. (2004). Guidelines for post-earthquake damage evaluation and rehabilitation of RC buildings in Japan. In 13th World Conference on Earthquake Engineering. Vancouver, Canada.

National Research Council Canada. (2005). National fire code in buildings. Ottawa, Canada: National Research Council Canada.

Organisation for Economic Co-operation and Development. (2004). Keeping schools safe in earthquake. Paris, France: OECD.
Remesh, K., \& Tan, K. H. (2007). Performance comparison of zone models with compartment fire tests. Journal of Fire Sciences, 25(4), 321-353.

SAP2000-V14. (2002). Integrated finite element analysis and design of structures basic analysis reference manual. Berkeley, California, USA.

Scawthorn, C. R. (2008). Fire following earthquake. The shake out scenario. California, USA: USGS-Science for Changing World.

Tanaka, T. (1998). Performance-based fire safety design of a high-rise office building. Japan: Building Research Institute.

Youssef, M. A., \& Moftah, M. (2007). General stress-strain relationship for concrete at elevated temperatures. Engineering Structures, 29(10), 2618-2634.

Zaharia, R., \& Pintea, D. (2009). Fire after earthquake analysis of steel moment resisting frames. International Journal of Steel Structures, 9(4), 275-284.

Zhao, J., \& Sritharan, S. (2007). Modeling of strain penetration effects in fiber-based analysis of reinforced concrete structures. ACI Structural Journal, 104(2), 133-141. 